\title{
Sistemas de espaços livres e esfera pública em metrópoles brasileiras
}

\author{
The systems of open spaces and public \\ sphere in brazilian metropolis
}

\author{
Eugênio Fernandes QueIroga \\ Doutor em Arquitetura e Urbanismo e professor da Faculdade \\ de Arquitetura e Urbanismo na FAU-USP \\ queiroga@usp.br
}

\section{Resumo:}

Os sistemas de espaços livres constituem um fundamental complexo para os processos de produção do meio urbano e da reprodução da vida nas cidades. Apresentam-se resultados de pesquisa sobre relaçóes entre sistemas de espaços livres e esfera pública em metrópoles brasileiras, onde se afirma a importância de ambos - espaço livre e esfera pública - para a qualidade da vida metropolitana.

Palavras-chave: sistemas de espaços livres, esfera pública, metrópoles brasileiras

\section{Abstract:}

The open space systems are fundamentals to production process of urban space and of the reproduction of the urban life. This paper shows research results about relationships between the open space systems and the public sphere in Brazilian metropolis. It affirms the importance of both - open space and public sphere - to the quality of the metropolitan life.

Keywords: Open space systems, public sphere, Brazilian metropolis 
1 - As RIDEs são as "regiões metropolitanas" ou "aglomerações urbanas" brasileiras que se situam em mais de uma unidade federativa. á são poucos os autores que afirmam existir um forte declínio da vida
pública e um uma biunívoca relação com a valorização da esfera de vida
privada. No Brasil são muitos os fatos que parecem apoiar tal percepção:

- no campo dos lançamentos imobiliários, os produtos prometem um mundo de alegrias, praticidades, vida saudável, proximidade com a natureza, felicidade! Tudo garantido por forte aparato de segurança privada, muros cada vez mais altos, encimados por cercas elétricas, helicoidais farpados, câmeras, etc.;

- os shopping centers retiram consumidores das áreas centrais tradicionais, buscando associar consumo e lazer de parcelas cada vez mais amplas da populaçáo, novamente tratam-se de espaços de alto controle e aparato de segurança privado. De forma análoga complexos multifuncionais (habitação, trabalho, compras e lazer) permitem a algumas pessoas realizar sua vida cotidiana "completamente" intra-muros;

- novas formas de telecomunicação e teleinformação prometem "trazer o mundo" até os portadores de telas e redes cada vez mais multifuncionais, dos i-phones aos home-teathers". Para que ir ao cinema se você pode levar o cinema até você? Se é possível fazer seu "filme", sua "música", sua "reportagem" e disponibilizar na internet? Diminui-se a necessidade dos contatos interpessoais presenciais para as açóes do trabalho, do lazer, dos relacionamentos sociais para os mais diversos fins.

Sem dúvida os fatos acima são cada vez mais frequentes, no entanto não são os únicos a caracterizar a vida nas metrópoles contemporâneas. Desde o doutorado (QUEIROGA, 2001) observa-se forte transformação nas práticas cotidianas dos habitantes metropolitanos ou mesmo megalopolitanos, mas tais alterações não enfraquecem a vida pública. Há sim mudanças na esfera pública, deslocamentos de práticas espaciais públicas, hibridismos, novas complexidades. Impossível afirmar, ao menos para as metrópoles brasileiras estudadas, que estejamos diante do "declínio do homem público", para usar expressão de importante autor americano (SENNET, 1988) que estuda a vida pública nos países centrais do capitalismo, em particular os Estados Unidos.

Os sistemas de espaços livres ainda apresentam relevância para a constituição da esfera pública? Esta foi a pergunta que norteou o Projeto Temático de Pesquisa intitulado "Os sistemas de espaços livres e a constituição da esfera pública contemporânea no Brasil", apoiado pela Fapesp e pelo CNPq, formulado pelo LABQUAPÁ da FAU-USP, onde tenho o prazer de participar como vice-coordenador. Para responder a esta questáo o projeto criou uma ampla rede nacional de pesquisa, intitulada QUAPÁ-SEL, que conta com a colaboração de inúmeros colegas, de universidades das cinco regióes do país. O projeto acabou em 2011, mas a rede continua com a proposta de compreender e colaborar para a qualificação dos espaços urbanos, local de vida de aproximadamente $85 \%$ da população brasileira.

Neste artigo apresentam-se resultados deste amplo esforço coletivo de pesquisa, no entanto, as incorreçóes que o texto possa apresentar são de responsabilidade única do autor deste trabalho.

As metrópoles pesquisadas foram Porto Alegre, Florianópolis, Curitiba, Maringá, São Paulo, Campinas, Rio de Janeiro, Belo Horizonte, Vitória, Salvador, Maceió, Recife, Natal, Fortaleza, São Luís, Belém, Manaus e Brasília. Esta última é oficialmente denominada de Região Integrada de Desenvolvimento do Distrito Federal e Entorno (RIDE). [1]

Constitui-se o primeiro quadro sobre os sistemas de espaços livres de im- 
portantes metrópoles do país. O conhecimento deste quadro permitiu também:

- avanço teórico-conceitual sobre o assunto, notadamente na relação entre sistemas de espaços livres e esfera pública contemporânea;

- estabelecer princípios de avaliação de sistemas de espaços livres urbanos;

- estabelecer critérios para a proposição de diretrizes para sistemas de espaços livres urbanos.

O volume de informaçôes e mesmo de síntese de resultados foi bastante grande, neste artigo problematizam-se sínteses importantes sobre as metrópoles investigadas. As especificidades dos lugares são muitas e relevantes, porém não são objeto deste trabalho.

\section{SISTEMAS DE ESPAÇOS LIVRES: ALGUNS CONCEITOS E POSIÇÓES FUNDAMENTAIS}

As formulaçóes conceituais de Milton Santos sobre o espaço constituem em referência central desta pesquisa. O espaço é entendido, pois, como um híbrido entre materialidade e sociedade, entre forma e conteúdo, entre fixos e fluxos, entre inércia e dinâmica, entre sistema de objetos e sistema de açóes. (SANTOS, 1996) Tem-se, portanto, o espaço como uma instância social, da mesma maneira que são instâncias sociais a economia, a cultura e a política. (SANTOS, 1985) Mais do que atentar para a dialética no espaço, impóe-se compreender a dialético do espaço, conforme propóe a geografia santosiana.

Os espaços livres são, pela definição de Miranda Magnoli (1982), todos os espaços "livres de edificaçáo", ou seja, todos os espaços descobertos, sejam eles urbanos ou não, vegetados ou pavimentados, públicos ou privados. Desta maneira, o estudo dos sistemas de espaços livres vai muito além das áreas verdes, dos espaços vegetados, dos espaços públicos, ao envolver todos os espaços livres.

Para Morin (2008, p. 157) o conceito de sistema exprime ao mesmo tempo unidade, multiplicidade, totalidade, diversidade, organização e complexidade. Um sistema é um objeto complexo, suficientemente aberto pois estabelece relaçôes com outros sistemas e suficientemente fechado, caso contrário não se constituiria como sistema. Um sistema implica elementos inter-relacionáveis, tais relaçôes (mais que os elementos em si) constituem uma organização e uma estrutura relativamente estável que caracteriza o objeto complexo (o todo sistêmico). A organização, por sua vez, contém dialeticamente as relações que definem o sistema e que o transforma, alterando sua estrutura, possibilitando sua permanência e contendo a possibilidade concreta de sua dissolução. Portanto, um sistema é sempre um processo, está sempre em movimento.

Ainda segundo Morin, um sistema é sempre um "sistema de sistemas". Pode-se pensar, portanto, em subsistemas (contidos pelo sistema em questão) ou suprassistemas que abrangem o sistema estudado.

Desta maneira, propóe-se entender o sistema de espaços livres (SEL) urbanos como os elementos e as relaçóes que organizam e estruturam o conjunto de todos os espaços livres de um determinado recorte urbano - da escala intra-urbana à regional. Como um sistema aberto, o SEL urbano se relaciona ao SEL regional, e assim sucessivamente, redefinindo-se reciprocamente em um processo dialético escalar.

O SEL urbano contém todos os espaços livres urbanos existentes num determinado recorte escalar, independentemente de sua dimensão, qualificação estética, funcional e fundiária. A idéia de sistema de espaços livres está vinculada à sua vinculação funcional e organizacional (socioambiental), já que fisicamen- 
te somente os espaços públicos estão conectados entre si, principalmente pelo sistema viário. Mesmo os espaços livres públicos não são, necessariamente, todos conectados fisicamente (vejam os pátios internos a algumas edificaçôes, por exemplo). A conexão física é apenas uma das inúmeras relações entre os espaços livres. A contribuição ambiental das áreas permeáveis e vegetadas de uma cidade, por exemplo, se constituem em importante serviço ambiental urbano, ainda que não necessariamente estejam conectadas fisicamente.

Parte-se, portanto, do princípio de que toda cidade possui um sistema de espaços livres. Este sistema está em constante processo de transformação e adequação às novas demandas e pressóes da sociedade (empresas, instituiçôes, classes e grupos sociais). O seu melhor atendimento as demandas cotidianas da sociedade vai depender das disponibilidades de recursos, dos padróes culturais existentes e, sobretudo, das decisóes políticas que podem levar a eventuais processos de qualificação ou desqualificação de tais sistemas.

O sistema de espaços livres é básico na existência da cidade porque:

- fundamental ao desempenho da vida cotidiana;

- fundamental na constituição da paisagem urbana, elemento da forma urbana, da imagem da cidade, sua história e memórias;

- participa da constituição da esfera de vida pública e da esfera de vida privada.

O conceito de sistema de espaços livres aqui proposto se sobrepóe, contém e amplia o conceito usual de "áreas verdes" frequentemente utilizado no país, que tem como base a necessidade de espaços livres dotados de vegetação. Esta é uma noção reducionista dos espaços livres, deixa de lado características fundamentais do espaço urbano, como a complexidade e diversidade das formas de apropriaçáo e apreensão social e o fato real da impossibilidade física e mesmo da inconveniência da existência de vegetação em determinados espaços livres.

A vegetação apresenta papel fundamental nas metrópoles brasileiras, é elemento essencial para a drenagem urbana, para microclimas mais agradáveis, para a biodiversidade e como fator de embelezamento urbano. Compreende-se, por outro lado, a importância dos espaços não vegetados para inúmeras práticas de relevância cultural: das feiras às festas populares, das manifestaçóes políticas à valorização de determinadas paisagens e patrimônios culturais.

Questiona-se, portanto, o "modelo único" e hegemônico, advindo de um conceito modernista e/ou americano-suburbano de espaços livres contínuos. Propôe-se, em contraposição, uma idéia mais abrangente, que extrapola limitaçôes físicas de conexão e de distância. Não há um tipo único ou ideal de sistema pois cada lugar urbano possui características específicas de formação histórica, características socioeconômicas e de relacionamento com o suporte biofísico.

\section{FORMA E DISTRIBUIÇÃo DOS ESPAÇOS LIVRES}

Os espaços livres públicos são aqueles bens de propriedade pública, com diferentes graus de acessibilidade e de apropriação. No Brasil, empregando as definiçóes de propriedade estabelecidas pelo Código Civil, podem-se classificar os espaços livres públicos em:

- bens de uso comum do povo: espaços de apropriação pública por excelência (a rua, a praça, o parque urbano, a praia, etc);

- bens de uso especial: destinados a atividades específicas (os espaços livres de uma escola pública ou de uma penitenciária, por exemplo); 

fetação.

- bens dominicais: os próprios de qualquer ente público passível de desa-

Os espaços livres públicos formam um subsistema dentro do sistema de espaços livres. O principal espaço livre urbano é a rua, elemento fundamental de conexão na cidade, por onde ocorre grande parte da vida cotidiana da sociedade urbana. Parques, praças, mirantes, calçadóes, promenades, unidades de conservação de proteção integral, lagoas, praias, rios, etc. se constituem nos demais elementos desse sistema.

O sistema de espaços livres públicos constituem no principal subsistema de espaços livres voltados à esfera de vida pública, notadamente os bens de uso comum do povo.

Os espaços livres privados estáo inseridos dentro das áreas particulares, ou são os terrenos privados desocupados. Tais espaços também se constituem num subsistema do SEL urbano. Nos espaços livres privados ocorrem inúmeras atividades do cotidiano da habitação e do trabalho, como descanso, recreação infantil, jogos, atividades do trabalho doméstico, estacionamento de veículos, etc. Jardins, quintais, estacionamentos, pátios de carga e descarga, etc. fazem parte deste sistema que, ao contrário do sistema de espaços públicos, só raramente apresenta conexão fisica, seus elementos encontram-se fragmentados e dispersos no tecido urbano das metrópoles brasileiras. Seu papel ambiental varia para cada forma do tecido urbano, evidentemente os espaços permeáveis, vegetados e arborizados prestam maiores serviços ambientais ao meio urbano.

O espaço livre na metrópole brasileira é comumente predeterminado a partir do processo de loteamento quando são especificadas e destinadas as áreas para as ruas e demais espaços públicos. A composição dos elementos edificados pode definir as características formais do espaço livre; no entanto, sua qualificação também deverá ser dada pelo seu desenho/projeto e pela manutenção adequada.

Somente em situações urbanas totalmente planejadas e implantadas sob rígido controle de seus promotores, sejam estes o Estado ou empreendedores privados, é factível a existência de uma distribuição equitativa dos tipos de espaços livres previamente idealizados. Este é o caso, por exemplo, de Maringá e Brasília.

$\mathrm{Na}$ urbanização contemporânea brasileira, empreendimentos privados de grandes proporçôes assumem, por vezes o papel de provimento de espaços livres formalmente bastante qualificados, no entanto, via de regra, apresentam acessibilidade muito reduzida e altamente controlada, enfraquecendo a esfera de vida pública. Tais empreendimentos vêm se realizando não apenas nas grandes metrópoles, mas também em cidades médias tais como São Carlos, Ribeirão Preto, São José do Rio Preto, São José dos Campos, Sorocaba, entre outros exemplos paulistas.

Há crescente dependência em relação ao mercado na constituição de sistemas de espaços livres (inter-relação entre espaços livres privados e públicos) em especial em áreas destinadas às elites. Vende-se cada vez mais produtos imobiliários que afirmam uma imagem "verde, tranquila e segura", quase sempre apresentam fortes impactos sociais, ambientais e paisagísticos que são sentidos apenas no médio prazo.

No país existem diversos padróes específicos de espaços livres. Em linha geral pode-se afirmar:

- para a habitação unifamiliar observa-se a presença dos quintais. A redução dessa forma a meros recuos laterais e de fundos é regra nos padrôes ha- 
bitacionais de renda média e a carência destes espaços meramente destinados à ventilação muito se observa nos padróes habitacionais ocupados pela população de baixa renda;

- para a habitação multifamiliar vertical ou horizontal é crescente a ocorrência de espaços livres de uso coletivo, evidentemente são maiores e mais elaborados aqueles destinados à população de maior renda, mas mesmo empreendimentos privados para famílias de renda entre 3 e 5 salários mínimos começam a incluir itens de lazer nos espaços livres condominiais;

- novos empreendimentos de maior porte (loteamentos e condomínios fechados, inclusive para fins industriais) apresentam certos cuidados ambientais, destinando áreas aos espaços de conservação ambiental, decorrentes, sem dúvida, do crescente rigor da aplicação da legislação ambiental na produção para o mercado formal no meio urbano;

- por conveniências do cotidiano, proprietários reduzem o espaço livre intralote, sobretudo quando ocupados por residência unifamiliar ou atividades do setor secundário (empresas de pequeno porte) ou terciário. É como se o espaço livre privado fosse apenas uma reserva para futura expansão das edificaçóes. O custo e o trabalho para se adquirir um novo imóvel capaz de abrigar as novas necessidades e exigências de famílias e empresas é alto, "justificando" a redução dos espaços livres da propriedade já em uso. Nos mapas sobre espaços livres intraquadra elaborados pelo LAB-QUAPÁ para cidades das metrópoles citadas confirma a exigüidade de espaços livres como regra geral. A grande maioria das áreas urbanas consolidadas apresenta espaços livres inferiores a $50 \%$ da área dos lotes, sendo as áreas com menos de $30 \%$ de espaços livres intralote a condição mais frequente.

\section{OS SISTEMAS DE ESPAÇOS LIVRES E A ESFERA PÚBLICA}

Quanto às relaçóes entre espaços livres e esfera de vida pública contemporânea vale lembrar a proposiçáo de Queiroga e outros (2009) que, apoiado em Habermas (2006 e 2007), consideram a existência correlacionada de:

- uma esfera pública geral, em sentido amplo, referente a toda vida em público;

- uma esfera pública política, em sentido estrito arendtiano, envolve as ações políticas.

Desta maneira os espaços livres públicos, sobretudo os bens de uso comum do povo, são, por excelência, espaços da esfera pública geral, podendo, em determinados eventos, constituírem espaços da esfera pública política. Deste modo, fica claro que para ampliar a esfera pública política é importante qualificar os espaços da esfera pública geral. Na medida em que se potencializa a vida em público, apresentam-se com maior clareza os conflitos, possibilita-se o estabelecimento da razão comunicativa (HABERMAS, 1989) enquanto razão pública (ROCHLITZ, 2002), portanto, política.

Se por um lado a urbanização brasileira apresenta crescente fragmentaçáo, por outro, com o aumento da mobilidade, eventos públicos (esportivos, culturais, políticos, etc.) podem se estabelecer com maior frequência e liberdade em espaços previstos ou não para isto, de acordo com planejamento governamental, empresarial, do terceiro setor ou mesmo a partir da ação de grupos sociais independentes. Tais situaçóes são freqüentes nos espaços públicos centrais, nos centros expandidos, nas periferias pobres das metrópoles e em seus parques mais importantes.

A materialidade integrante do espaço pode ou não potencializar a esfera 
pública. A vida em público pode ser diminuída, por exemplo, ao se permitir o fechamento de uma rua, de um bairro, de uma favela, ou não se investindo na qualidade e distribuição de espaços livres de diferentes tipos e escalas.

Se a vida privada e social tem nos espaços edificados seu maior suporte, a vida pública tem nos espaços livres, sobretudo nos espaços livres públicos, seu maior suporte físico-material para ocorrer, são eles os espaços de maior acessibilidade, de maior capacidade para receber a diversidade, a pluralidade e o imprevisto, características de uma esfera pública mais rica. Evidentemente os espaços livres públicos não se constituem no único suporte para a esfera pública, a internet e outros meios de comunicação também são elementos com crescente importância para a esfera pública. Observa-se não uma oposição entre tais meios - reais e virtuais -, mas o estabelecimento de relaçóes sistêmicas entre eles, permitindo compreender a esfera pública como um sistema de açóes que se realiza a partir de um sistema de objetos espaciais - concretos ou virtuais -, constitutivo de um sistema de símbolos e valores culturais.

Os lugares públicos não são, via de regra, formados apenas pelos espaços livres públicos, mas sim pelos sistemas de espaços livres e edificados onde se desenvolve a vida em público. Desta maneira busca-se apreender a esfera pública contemporânea brasileira em suas diferentes manifestaçôes nos mais diversos lugares onde ela se estabelece, tais como: os centros históricos das cidades com suas praças, igrejas, calçadóes, prédios públicos e particulares voltados ao trabalho e à moradia, bairros como a Lapa no Rio de Janeiro, a Ilha das Caieiras em Vitória, as praias urbanas de todas as metrópoles litorâneas do país, os campinhos de futebol nas periferias das metrópoles, estejam elas em grandes, médias ou pequenas cidades, de São Paulo à Suzano, Recife à Suape, Belo Horizonte a Brumadinho, etc. Mesmo grandes shopping centers, como o Shopping D. Pedro em Campinas, apresentam tamanha diversidade de formas de apropriaçáo e a presença de diferentes grupos sociais que impedem considerá-los apenas simples espaço de consumo das classes médias.

Neste sentido, as manifestações políticas no espaço livre público, constituidoras da esfera pública política, são como a ponta de um iceberg, formado por toda a vida em público (esfera pública geral), realizada, sistemicamente, nos mais diversos lugares urbanos.

\section{A PROdUÇÃo E GESTÁo dOS SISTEMAS DE ESPAÇOS LIVRES}

As oficinas de pesquisa realizadas nas cidades investigadas pelo Projeto Temático QUAPÁ-SEL permitiram a compreensão de um amplo quadro de problemas comuns de gestão a quase todas as metrópoles estudadas. São muitas as boas iniciativas de produção de espaços livres públicos em inúmeros municípios, revelando a importância crescente do tema, mas geralmente sofrem da descontinuidade administrativa e da falta de inserção em planejamento mais integrado.

O espaço livre náo faz parte formalmente do status de infra-estrutura urbana, exceção é o sistema viário, porém este continua privilegiando o automóvel, relegando para segundo plano o transporte público e para o terceiro plano o pedestre e o ciclista. Os espaços livres não estão entre as prioridades dos poderes públicos, ainda que isto acarrete em crescentes desastres ambientais anunciados e verificados anualmente na época das chuvas torrenciais (alagamentos, deslizamentos, destruição e mortes).

O processo de planejamento de sistemas de espaços livres é ainda inexisten- 
te ou muito incipiente nas cidades metropolitanas, o que dirá de um planejamento efetivamente metropolitano. Observa-se uma multiplicidade de agentes produtores e gestores que dificulta a ação planejada ou coordenada, a desarticulação e sobreposição de funçóes entre secretarias acarretam conflitos de competências, além disto, a cada mudança de gestão é freqüente a alteração de secretarias e de suas atribuiçóes no que tange ao trato dos espaços livres.

A arborizaçáo urbana é bastante ausente da maioria dos tecidos urbanos metropolitanos. As calçadas são, em grande parte, estreitas, as áreas de urbanização periférica são pouquíssimo arborizadas. Raras são as cidades que contam com planos de arborização em implantação mais continuada. Maringá é raro exemplo, fazendo inclusive com que cidades do entorno acabaram adotando a cultura da arborização viária. Em São Paulo, por exemplo, atualmente ocorre plantio arbóreo pouco criterioso, não planejado, mas muito intenso, decorrente do cumprimento de compensaçóes resultante do licenciamento ambiental de novos empreendimentos privados e públicos. Lamentavelmente as perdas nestes plantios são enormes.

Observa-se grande falta de tratamento paisagístico adequado na maioria dos espaços públicos, as maiores exceçóes são as áreas centrais (maior visibilidade) e bairros de renda alta. As iniciativas recentes de melhoria dos espaços livres públicos nos bairros mais pobres (Vitória, São Paulo, Rio de Janeiro, Belo Horizonte, Belém e Campinas) apresentam, por vezes, projetos inadequados à grande demanda e, via de regra, não são acompanhados de manutenção adequada ao intenso uso. É frequente, nestes contextos, a alta depredação e a deplorável apropriação pelo tráfico de drogas.

A precariedade dos transportes públicos (exceção maior é Curitiba) não facilita a acessibilidade aos parques, ainda assim observa-se sua crescente utilização, sobretudo nos finais de semana. A conservação dos parques é variável, de cidade a cidade, de bairro a bairro, indo de muito precária a muito boa.

Há crescente tratamento de orlas de rios, mares e lagoas, mas ainda existem muitas orlas sem qualificação paisagística e urbanística. O conflito entre a legislação ambiental vigente, as demandas de uso e os projetos realizados impóe que se revise os procedimentos legais, propositivos e de manutenção. Nas metrópoles litorâneas, trechos de orla mais voltados ao turismo e à moradia das elites são reformados a todo instante, instalando-se novo mobiliário urbano, trocando-se o piso, etc. É grande o desequilíbrio de tratamento verificado nestas metrópoles entre os espaços livres de orla e os periféricos.

A precariedade do saneamento ambiental infesta de esgoto, poluição difusa e resíduos sólidos boa parte dos cursos d'água das metrópoles brasileiras. As áreas de preservação permanente (APPs) urbanas junto aos corpos d'água apresentam alta degradação e se constituem em espaços que fragmentam o tecido urbano, ou quando deles participam, apresentam tratamento paisagístico bastante precários. Exceção costumeira é a dos espaços junto à moradia de alta renda, porém, mesmo em "bairros nobres" é comum as APPs encontrarem-se em mal estado de conservaçáo.

Em diversas metrópoles investigadas (por exemplo: Rio de Janeiro, Belém, Campinas, entre outras) terras públicas das forças armadas se apresentam como barreiras à urbanização, podendo, no futuro, representar importante parcela de estoque de espaços livres para convívio e conservação ambiental.

Não são poucos os desafios para a ampliação e qualificação dos SELs das metrópoles brasileiras, envolvem principalmente as seguintes questóes:

- necessidade de uma legislação urbanística-ambiental mais adequada às 
especificidades ambientais urbanas;

- saneamento ambiental;

- revisão de paradigmas urbanísticos que priorizam a circulação de automóveis e caminhôes e que regem a produção imobiliária voltada ao mercado solvente;

- estabelecimento de planos de sistemas de espaços livres atentos à realidade dos diferentes lugares urbanos;

- articulação das políticas públicas;

- capacitação dos quadros técnicos que planejam, projetam, executam e mantém os espaços livres.

\section{Critérios para o estabelecimento de Diretrizes}

A abordagem sistêmica utilizada para a análise dos espaços livres urbanos das metrópoles brasileiras permite conceber critérios para o estabelecimento de diretrizes para a qualificação de sistemas de espaços livres urbanos de maneira mais complexa. Diante da heterogeneidade de situaçóes geoclimáticas, históricoculturais e econômicas das metrópoles brasileiras, considera-se absurda qualquer idéia de modelo ou de "manual" para "o bom sistema de espaços livres".

Propóe-se pensar um sistema metapropositivo, diferentemente de um simples elenco - tipo check-list - de itens avaliados ou de recomendações de projeto, tão comuns na bibliografia de origem norte-americana e táo limitador das inúmeras combinaçóes positivas que pode melhor aderir à determinada situação metropolitana, num dado momento histórico, político e econômico.

A vida cotidiana e a esfera pública apresentam diversas formas de apropriação do espaço livre, variando em função das demandas dos diversos grupos sociais, do clima e sua sazonalidade, da presença ou não de determinados equipamentos, do entorno edificado, do dia (de semana ou fim de semana) ou da noite, de eventual programaçáo promovida por instituiçóes, empresas, ONGs e grupos sociais, das condições de (in)segurança, da inserção do referido espaço em relação ao sistema de espaços livres. Neste sentido recomenda-se que um sistema de espaços livres possua diferentes tipos de espaço para possibilitar as mais variadas práticas de apropriaçóes públicas. Deve-se buscar a multifuncionalidade mais do que os usos exclusivos sempre que possível. Assim uma quadra de esportes pode se prestar para uma festa religiosa, uma apresentação de hip-hop ou mesmo uma noite de serestas.

Um sistema de espaços livres urbanos deve se prestar, por exemplo, para as seguintes demandas:

- espaços públicos: circulação, acesso e convívio de pedestres, circulação, acesso e estacionamento de veículos (da bicicleta ao veículo leve sobre trilhos), áreas de estar, convívio, recreação e contemplação da paisagem, áreas de atividades físico-desportivas, áreas de conservação ambiental, espaços para manifestaçôes políticas, artísticas e culturais, áreas para feiras, festas comunitárias, eventos circenses e religiosos, espaços destinados a usos específicos (ligados aos sistemas infra-estruturais de energia, saneamento ambiental, comunicaçóes, portos e aeroportos, espaços de educação e pesquisa, entre outros);

- espaços privados: convívio familiar e social, recreação e contemplação, apoio aos espaços edificados (conforto ambiental, áreas de carga e descarga, estacionamentos, etc.), trabalho e serviços ambientais propiciados pela presença de áreas permeáveis, áreas vegetadas, arborizadas.

Vale observar que a ideologia ambientalista vem se difundindo em todos 
os meios, dos centros de pesquisa às atividades domésticas cotidianas. Novas propostas de espaços de conservação ambiental têm maiores chances de serem estabelecidas do que no passado recente. Necessário não isolar a questão ambiental das questôes sociais (econômicas e culturais), potencializando assim uma gestão e apropriação mais adequada das áreas de conservação ambiental.

O princípio da equiacessibilidade aos espaços livres públicos de convívio e lazer deve ser garantido. Para tanto é fundamental estabelecer um sistema que considere a distribuição de tais espaços no território urbano e a sua acessibilidade pelos diferentes meios de transporte.

É preciso atentar para a crescente capacidade de deslocamentos intermunicipais de parcelas cada vez mais significativas da sociedade metropolitana brasileira para fins de ócio e lazer. Tem-se concretamente a apropriação por diversos grupos sociais de um sistema de espaços livres (municipal), dentro de outro sistema (regional ou extra-regional). Novos tipos de espaços livres para estas escalas podem ser propostos, como os parques regionais (QUEIROZ, QUEIROGA, 2010) e as estradas-parque onde se deve garantir a apreensão e uso da paisagem, mesmo sobre propriedades privadas rurais, constituindo uma forte relaçáo complementar entre propriedades públicas e privadas, orientadas por questóes da paisagem e do ambiente.

O princípio da diversidade deve ser perseguido, não apenas a biodiversidade como a sociodiversidade e a garantia à diversidade cultural. Hábitos tradicionais e novos, endógenos e exógenos estão sempre em relação dialética, os espaços livres públicos são suporte importante para sua manifestação, contendo elemento educador na medida em que propicia a visibilidade e, quem sabe, o respeito pela alteridade.

\section{Concluindo}

Diante dos padrốes culturais, das ideologias urbanísticas e paisagísticas exógenas e das motivaçóes econômicas que regem a lógica dialética contemporânea das relaçôes entre o Estado brasileiro e o capital imobiliário, torna-se fundamental discutir os padróes urbanísticos de produção das metrópoles do país. A definição prévia, conceitual e formal, do sistema de espaços livres públicos deve preceder a formalização de qualquer assentamento urbano. $O$ espaço público deve ser elemento indutor aos projetos urbanos, considerando, evidentemente, as especificidades socioambientais locais. É necessário considerar o sistema de espaços livres de forma prioritária e integrada para a constituição de um ambiente metropolitano mais adequado às práticas sociais, à esfera pública e à conservação ambiental. A qualidade de vida propiciada pela urbanização não pode selecionar esta ou aquela classe social, pelo contrário, deve ser considerado um direito do cidadão.

Como falar em um "novo" direito do cidadão - a urbanidade - se nossa urbanização ainda apresenta carências elementares? Não se trata, evidentemente, de priorizar os investimentos em sistemas de espaços livres em detrimento de setores como educação, saúde e habitação. O que se pretende é a integraçáo de políticas públicas, compreendendo que:

- morar é mais do que possuir uma casa, é conviver, inclusive nos lugares públicos;

- educar envolve a cidade, seus espaços públicos, compreendendo a existência do outro, respeitando diferenças, construindo um cotidiano comunicacional 
político participativo;

- um ambiente saneado, com microclima adequado, menos poluído, é item de saúde pública, assim como oportunizar espaços livres voltados ao lazer e atividades físicas contribui para a qualidade de vida da população;

- a conservação de várzeas e morros vegetados é garantia de menos enchentes, deslizamentos de terra, perdas materiais e, sobretudo, humanas;

- a mobilidade das pessoas não terá solução viável nas grandes metrópoles se baseada no automóvel, a rua é espaço do cidadão e não deste ou daquele veículo.

Propor a qualificação dos sistemas de espaços livres é, portanto, contribuir para a educação, saúde, transportes, habitação, saneamento e meio ambiente. É construir uma metrópole melhor, pensando espaços de cidadania mais do que de consumo.

\section{REFERÊNCIAS BIBLIOGRÁFICAS}

BRASIL. Lei 10.406/02, Capítulo III, disponível em <www.planalto.gov.br/ccivil/leis/2002/L10406.htm>, acessado em mar./2011.

HABERMAS, J. The theory of communicative action (1981). Boston: Beacon Press, 1989. 2 v., v. 2. Lifeworld and system: a critique of funcionalist reason. . Entre naturalismo y religión (2005). Barcelona: Paidós, 2006.

. A inclusão do outro: estudos de teoria política (1996). 3. ed. São Paulo: Loyola, 2007.

MACEDO, S. et. al. "Consideraçôes preliminares sobre o sistema de espaços livres e a constituição da esfera pública no Brasil”. In TÂNGARI, V., ANDRADE, R., SCHLEE, M. (Orgs.). Sistema de espaços livres: o cotidiano, apropriaçôes e ausências. Rio de Janeiro: Universidade Federal do Rio de Janeiro, Faculdade de Arquitetura e Urbanismo, Pós-Graduação em Arquitetura, 2009. 60-83.

MAGNOLI, Miranda M. E. M. "Espaços livres e urbanização: uma introdução a aspectos da paisagem metropolitana". 1982. Tese (Livre-docência) - Faculdade de Arquitetura e Urbanismo, Universidade de São Paulo, São Paulo.

MORIN, E. O método 1:: a natureza da natureza. Porto Alegre: Sulina, 2008.

QUEIROZ, A, QUEIROGA, E. "Novos processos urbanos e a implantação de parques regionais contemporâneos: estudo de caso na regiâo de Limeira SP”. In $10^{\circ}$ ENEPEA - Encontro Nacional de Ensino de Paisagismo em Escolas de Arquitetura e Urbanismo no Brasil. Anais. Porto Alegre: PUC-RS, 2010. 1-12. (CD-ROM)

QUEIROGA, E. et. al. "Os espaços livres e a esfera pública contemporânea no Brasil: por uma conceituação considerando propriedades (públicas e privadas) e apropriaçóes". In TÂNGARI, V., ANDRADE, R., SCHLEE, M. (Orgs.). Sistema de espaços livres: o cotidiano, apropriaçôes e ausências. Rio de Janeiro: Universidade Federal do Rio de Janeiro, Faculdade de Arquitetura e Urbanismo, Pós-Graduação em Arquitetura, 2009. 84-99.

ROCHLITZ, Rainer (coord.). Habermas: o uso público da razão (2002). Rio de Janeiro: Tempo Brasileiro, 2005.

SANTOS, M. Espaço e método. São Paulo: Nobel, 1985.

. A natureza do espaço: técnica e tempo, razão e emoção. São Paulo:

Hucitec, 1996. 